\title{
ДЕНТАЛЬНАЯ ИМПЛАНТАЦИЯ И КУРЕНИЕ: СОВРЕМЕННОЕ СОСТОЯНИЕ ПРОБЛЕМЫ
}

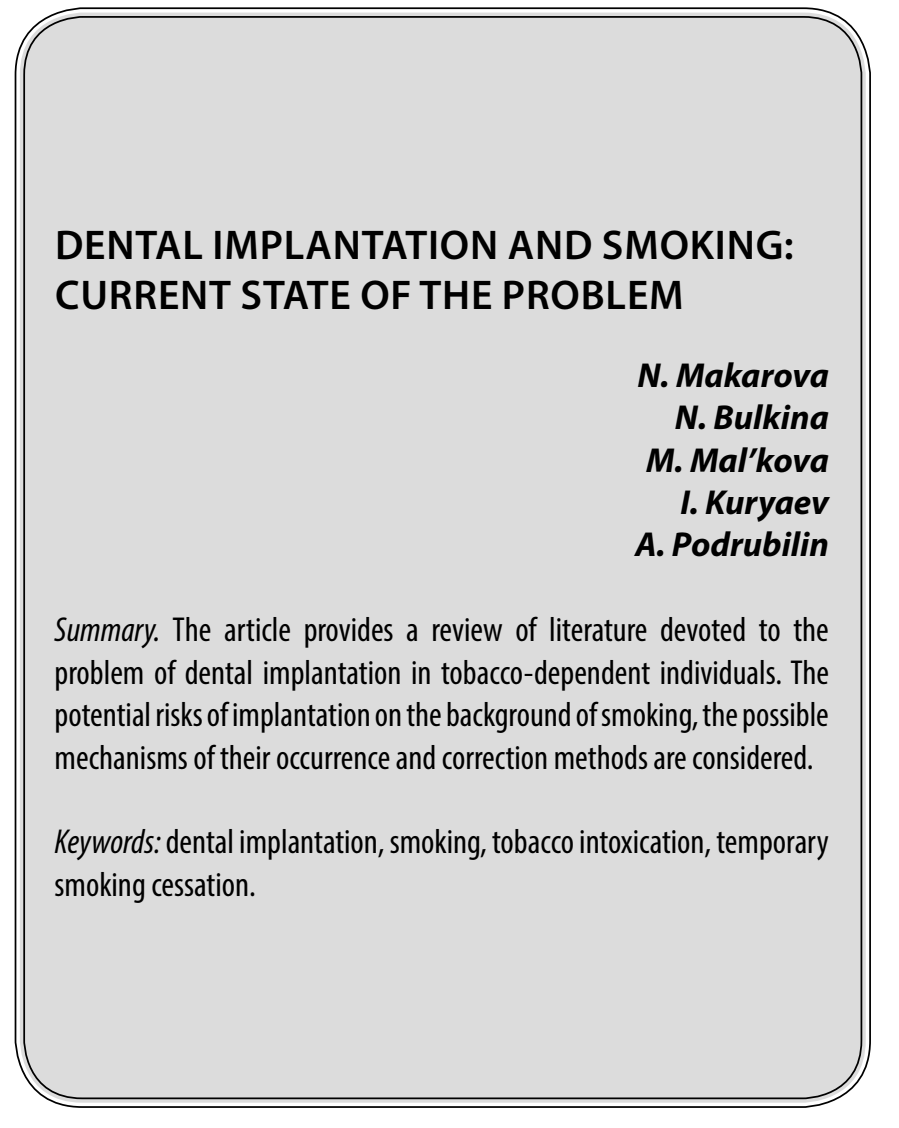

\section{Ввецение}

$\mathbf{H}$ а сегодняшний день известно, что курение является фактором риска развития и прогрессирования многих хронических заболеваний, в том числе болезней сердечно-сосудистой, дыхательной, репродуктивной и других систем организма, в том числе злокачественных новообразований [1].

По данным Всемирной организации здравоохранения, в 2019 году в мире насчитывалось более 1 миллиарда курильщиков, а смертность от ассоциированных с курением заболеваний составляет более 8 миллионов человек в год [2].

Для борьбы с табакокурением и его последствиями ВО3 была разработана рамочная конвенция, содержащая положения о повышении цен и налогов на табак, а также другие меры. Однако высокий налоговый доход от продаж табака в совокупности с большим количеством курильщиков может сдерживать активность пра-
Макарова Надежда Игоревна

Старший преподаватель, Пензенский государственный университет zidanzinedin@yandex.ru

Булкина Наталия Вячеславовна

Д.м.н., профессор, Саратовский государственный медицинский университет им. В.И. Разумовского

navo@bk.ru

Малькова Мадина Ильясовна

Пензенский государственный университет appl.non@mail.ru

Куряев Ильнур Рафикович

Пензенский государственный университет ilnurelyzan@yandex.ru

Подрубилин Артём Вячеславович

Пензенский государственный университет eminemlion@gmail.com

Аннотация. В статье приведен обзор литературных источников, посвященных проблеме дентальной имплантации у лиц с табачной зависимостью. Рассмотрены потенциальные риски проведения имплантации на фоне курения, возможные механизмы их возникновения и способы коррекции.

Ключевые слова: дентальная имплантация, курение, табачная интоксикация, временная отмена курения.

вительств некоторых стран от участия в антитабачной кампании.

Существует большое количество научных исследований, показывающих неблагоприятное воздействие курения на состояние ротовой полости. Нарушение вкуса, сухость во рту, галитоз, образование специфических пигментированных зубных отложений являются частыми спутниками табакозависимости [3-5].

Показано, что табачный дым оказывает негативное воздействие на состояние микроциркуляторного русла в парадонте, вызывая спазм сосудов, повышение гематокрита и склонности к тромбозу. Нарушения трофики тканей сопровождаются деструкцией коллагеновых волокон, снижением минеральной плотности альвеолярной кости [6].

У курильщиков отмечается изменение качественного состава микрофлоры полости рта, что приводит к уменьшению количества микробов-комменсалов, являющих- 
ся антагонистами патогенной микрофлоры и, соответственно, к активации условно-патогенных и патогенных микроорганизмов (гемолитический стрептококк, золотистый стафилококк, грибы Candida и др.) [7].

В условиях гипоксии снижаются защитные силы пародонтальных тканей, что, в совокупности с активацией патогенной микрофлоры, выявленной у курильщиков, создает благоприятную почву для развития заболеваний пародонта. Патология пародонта на фоне курения возникает в 2,5-6 раз чаще, чем у некурящих [8]. Прогрессирование течения пародонтита влечет за собой разрушение зубодесневого прикрепления и потерю зубов.

Протезирование дефектов зубного ряда с помощью конструкций, опирающихся на дентальные имплантаты, получило широкое распространение в последние десятилетия. Однако, с точки зрения имплантологии, табакокурение также является фактором риска.

Одно из первых исследований, выявивших связь между курением и частотой осложнений дентальной имплантации, было проведено Bain С.А. и Моу Р.К. в 1993 году [9]. В ходе исследования за шестилетний период в группе из 540 пациентов, которым были установлены дентальные имплантаты, общая частота неудач составила 5,92\%, что согласовалось с другими исследованиями. После разделения пациентов на курящих и некурящих было обнаружено, что значительно больший процент неудач зарегистрирован у курильщиков $(11,28 \%)$, по сравнению с группой некурящих $(4,76 \%)(\mathrm{P}<$ 0,001). Результаты этого исследования впервые показали, что курение может снижать вероятность успешного исхода имплантологического лечения.

Bain C.А. и Моу Р.К. также обнаружили взаимосвязь между интенсивностью потребления табака и увеличением частоты отторжения имплантатов. Авторы выявили, что распространенность кости IV типа (по классификации U. Lekholm, G. Zarb (1985): кость со значительным преобладанием губчатого вещества низкой плотности) была в два раза выше среди интенсивно курящих людей по сравнению с некурящими или даже с мало курящими [10].

Анализ годовой и 5-летней выживаемости имплантатов системы «Bicon» (Bicon Inc, США) показал, что у курильщиков риск неудачи в 4,3 раза выше, чем у некурящих. При чем худшие показатели выживаемости имплантатов как в краткосрочной, так и в долгосрочной перспективе у курильщиков отмечались при одноэтапном протоколе имплантации [11].

Другие исследования, включавшие наблюдения более чем за 1000 установленных дентальных имплантатов, показали сходные результаты, но с меньшими различиями между группами курящих и некурящих: Deluca S. et al. (2006) - 23,1\% неудач у курильщиков против 13,3\% у некурящих пациентов, Arora A. et al. (2017) - 6,9\% против 1,8\%, Gupta A. et al. (2018) - 5,6\% против 2,4\%, соответственно. При этом как неудача расценивались боль, воспаление или подвижность в области имплантата[12-14]. Анализ случаев несостоятельности и осложнений при имплантации у курильщиков показывает зависимость от локализации ложа имплантата на верхней или нижней челюсти, стажа курения и его интенсивности.

Большее количество неудач имплантологического лечения, как правило, ассоциировано с имплантатами, установленными на верхней челюсти $[12,14]$, хотя есть сообщения о худших результатах лечения на нижней челюсти [15].

Важными критериями при оценке влияния курения на результаты дентальной имплантации являются стаж курения и количество выкуриваемых сигарет в день. Большинство исследований демонстрируют повышение уровня неудач при продолжительности курения более 10 лет и потреблении более 20 сигарет в день, по сравнению с некурящими [14-16]. Однако, при сравнении показателей успешности имплантации у курильщиков с различными стажем и интенсивностью курения между собой, результаты несколько разнятся $[13,14,16]$.

В работах Shenava S. et al. (2016), Arora A. et al. (2017) отмечается большее количество неудачных исходов имплантологического лечения у пациентов, курящих более 10 лет и потребляющих более 20 сигарет в день по сравнению с теми, кто курит менее интенсивно, но найденные различия статистически не значимы $[13,17]$.

Cakarer S. et al. (2014), проанализировав показатели выживаемости 940 установленных имплантатов, не выявили значимого влияния курения на результаты имплантации [18].

Большой интерес представляет ретроспективное исследование Twito D., Sade P. (2014) проанализировавших результаты установки более чем 7500 дентальных имплантатов. Авторы выявили не только значительные различия между курящими и некурящими, но и различия внутри группы курящих пациентов, разделив их на множество подгрупп в зависимости от стажа, интенсивности курения и других дополнительных критериев. В частности, установлено, что при длительности курения более 10 лет риск неудачи возрастал в 1,7 раза по сравнению с пациентами с меньшим стажем курения, а потребление более 30 сигарет в день повышало риск неудачи в 1,6 раза по сравнению с менее «злостными» курильщиками. Также был учтен фактор пассивного курения в замкну- 
тых помещениях, что повышало вероятность негативного исхода имплантации в 2,3 раза [15].

Важным показателем состоятельности дентального имплантата является стабильное состояние окружающей его костной ткани. Известно, что после нагружения дентального имплантата из-за ремоделирования окружающих тканей, а также вследствие воздействия целого комплекса эндо- и экзогенных факторов, происходит постепенная убыль костной ткани [19].

Исследования, направленные на изучение данной проблемы за последние 15 лет, показывают значимые различия убыли периимплантатной костной ткани у пациентов в зависимости от наличия или отсутствия фактора табакокурения, с более прогрессивной потерей маргинальной кости у курящих пациентов $[20,21]$.

В мета-анализе Clementini M. et al. (2014) на основании данных 13 исследований установлено, что среднегодовой показатель убыли костной ткани вокруг имплантатов у курильщиков на 0,164 мм выше, чем у некурящих [22].

Mumcu E. et al. (2019) отмечают значительно большую глубину зондирования и потерю периимплантатной костной ткани у курильщиков через один и три года после протезирования, при этом не было выявлено статистически значимых различий данных параметров у пациентов в зависимости от пола и локализации имплантата в различных участках верхней или нижней челюсти [23].

Среди механизмов патогенетического действия табакокурения на организацию тканей вокруг дентального имплантата указывают негативное влияние никотина на клетки костной ткани. Из-за сложностей забора биологического материала у пациентов, большинство исследований по данной тематике проводится в экспериментальных исследованиях, - in vitro или in vivo.

В исследованиях in vitro показано, что воздействие экстракта табачного дыма понижает распространение, пролиферацию и дифференцировку преостеобластических клеток на поверхности титана. Кроме того, вследствие адсорбции углеродсодержащих компонентов табачного дыма изменялась микроморфология поверхности титана, что, в итоге, оказывало влияние на взаимодействия между ней и остеобластами $[24,25]$.

Zhao X. et al. (2018) на небольшой выборке показали снижение пролиферации и дифференцировки стволовых клеток костного мозга альвеолярной кости, полученных от курящих пациентов во время операции дентальной имплантации [26].
Также необходимо отметить влияние компонентов сигаретного дыма на состояние микроциркуляции крови в тканях пародонта и имплантационного ложа, поскольку состояние локального кровоснабжения имеет определяющее значение для обеспечения высоких энергетических и пластических потребностей в зоне регенерации, а также поступления клеток крови и синтезируемых ими факторов роста, необходимых для начальных этапов процесса остеоинтеграции дентального имплантата [27].

Отечественные и зарубежные исследования демонстрируют, что воздействие никотина вызывает вазоконстрикцию, что влечет за собой снижение перфузии тканей кровью и, как следствие, ишемию $[28,29]$.

В развитии таких осложнений дентальной имплантации, как периимплантит, мукозит значительную роль играет инфекционное воспаление. Ухудшение гигиенического состояния полости рта, регистрируемое у курильщиков, создает для него весьма благоприятную среду [3].

Al-Zyoud W. et al. (2019) с помощью метода высокопроизводительного секвенирования нового поколения (NGS) бактериальной ДНК выявили изменения состава микробиома слюны у курящих испытуемых, по сравнению с некурящими. В частности, отмечена большая распространенность родов Streptococcus, Veilonella, Prevotella в образцах, полученных от табакозависимых лиц [30].

Биологические изменения среди ключевых патогенных микроорганизмов, таких как Porphyromonas gingivalis, вместе со сниженным иммунным ответом могут способствовать изменениям поддесневой микрофлоры у курильщиков. Также имеются сообщения о развитии дисбиоза пародонтальной микрофлоры на фоне курения как при отсутствии клинических признаков воспаления, так и после терапевтического лечения заболеваний пародонта [31, 32].

Большое значение для развития инфекционно-воспалительных осложнений имеет адгезия бактерий. Несмотря на имеющиеся данные о негативном влиянии табакокурения на состав и свойства микробной бляшки, до настоящего момента нет единого мнения о его значимости. Однако, по-прежнему, гладкость поверхности супраконструкции, своевременная и качественная ее очистка являются ключевыми факторами долговременной службы дентальных имплантатов [33, 34].

Наиболее предпочтительным способом снижения и устранения обусловленных курением рисков для здоровья и, в том числе, для дентальной имплантации, без- 
условно, является полный отказ от вредной привычки. Однако зачастую курильщики не имеют достаточной мотивации для столь решительного шага. В качестве компромиссных мер были предложены протоколы временной отмены курения.

Bain C. (1996) указывает на значительное снижение доли неудач при дентальной имплантации у пациентов, придерживающихся протокола, который предполагал отказ от курения на 1 неделю до операции и 8 недель после нее [35].

Peleg M. et al. (2006) сообщает об успешных результатах дентальной имплантации на верхней челюсти, проведенной одномоментно с открытым синуслифтингом у курильщиков при применении оптимизированного протокола отмены. Данный протокол включал постепенное снижение потребления сигарет на 2-5 штук в день за неделю до операции, с последующей полной отменой курения на 1 день до и неделю после вмешательства. Предполагается, что более «мягкие» меры повышают вероятность того, что они будут соблюдены пациентами [36].

Таким образом, за последние десятилетия накоплено большое количество исследований о влиянии курения на исход дентальной имплантации. Безусловно, при ана- лизе результатов имплантации у курящих пациентов необходимо принимать во внимание возможное наличие других общих и локальных факторов риска, способных оказывать влияние на успешность лечения. Поскольку клинические исследования не позволяют рассматривать изолированно влияние фактора табакокурения на организацию периимплантатных тканей и имеют существенные этические ограничения, исследования in vitro и in vivo не теряют актуальности. Использование современных лабораторных и инструментальных методов открывают огромные возможности для раскрытия патогенетических механизмов воздействия курения на заживление тканей в области дентального имплантата и разработке способов оптимизации репаративных процессов.

Практические рекомендации при планировании имплантации у курильщиков включают тщательный опрос и обследование пациентов с целью выявления длительности и интенсивности курения, наличия сопутствующей патологии и уровня гигиенических навыков. Необходимо информировать пациентов о возможных рисках для дентальной имплантации, сопряженных с курением, и тем самым создавать мотивацию для отказа от этой привычки. В качестве альтернативной меры может быть предложена временная отмена курения в периоперационном периоде и/или снижение потребления сигарет.

\section{ЛИТЕРАТУРА}

1. Оболонкова, Н. И. Влияние курения на состояние здоровья и развитие онкологических заболеваний человека / Н. И. Оболонкова, Ю. А. Гордиенко // Сб. матер. 16-й Международной научно-практической конференции «Наука и образование: отечественный и зарубежный опыт».—- Белгород, 2018. - С. 245-250.

2. World Health Organization. Geneva. WHO report on the global tobacco epidemic 2019: offer help to quit tobacco use. — 2019.

3. Чжан Лэй. Влияние фактора курения на гигиенические и кинические показатели стоматологического здоровья / Чжан Лэй, В.М.Гринин, В.Н.Царев // Dental Forum.-2012.— № 4.- C. 45-46.

4. Mammadov, Yu. F. The importance of smoking in the genesis of diseases of the organs and tissues of the oral cavity / Yu. F. Mammadov, D. A. Safarov, A. V. Orujov, E. R. Alieva // Theoretical \& Applied Science.—2019.— № 3 (71). — C. 379-384.

5. Кубанов, И. М. Влияние курения на состояние тканей полости рта. Распространенность курения среди студентов СГМУ / И. М. Кубанов, А. А. Курбанов, К. Б. Хапчаев// Бюллетень медицинских интернет-конференций. — 2018. - Т. 8, № 3. — С. 124-125.

6. Ибрагим, Р. Х. Влияние курения табака на состояние микроциркуляции крови в десне / Р. Х. Ибрагим, В. И. Козлов, 0. А. Гурова // Лазерная медицина.2017. 一 Т. 21, № 3.— C. 40-43.

7. Кушубеков, Д. К. Сравнительная характеристика нормальной микрофлоры полости рта у курящих и некурящих студентов / Д. К. Кушубеков // Вестник КГМА им. И. К. Ахунбаева.— 2016. - № 6.- С. 60-63.

8. Мхитарян, А. К. Влияние курения на состояние пародонта / Мхитарян А. К., Тихонова Н. Н., Хадарцева И. В. // Вестник молодого ученого.- 2012.— № 2. - C.12-13.

9. Bain, C.A.The association between the failure of dental implants and cigarette smoking / C. A. Bain, P. K. Moy // Int J Oral Maxillofac Implants. — 1993._Vol. 8. — P. 609-15.

10. Bain, C. A. The influence of smoking on bone quality and implant failure / C. A. Bain, P. K. Moy // Int J Oral Maxillofac Implants. — 1994. — Vol. 9.—P.123.

11. Vehemente, V. A. Risk factors affecting dental implant survival / V. A. Vehemente, S. K. Chuang, S. Daher, A. Muftu, T. B. Dodson // J Oral Implantol. - 2002. - Vol. 28.-P. 74-81.

12. Deluca, S. The effect of smoking on osseointegrated dental implants.Part I: Implant survival / S. Deluca, E. Habsha, G. A. Zarb // The International Journal of Prosthodontics. - 2006. - Vol. 19. - P. 491-498.

13. Arora, A. Comparative evaluation of effect of smoking on survival of dental implant/ A. Arora, M. M. Reddy, S. Mhatre, A. Bajaj, P. V. Gopinath, P. Arvind // J Int Oral Health. - 2017. - Vol. 9. - P. 24-7. 
14. Gupta, A. Nicotine, the Predictor of Success or Failure of Dental Implants: A Retrospective Study / A. Gupta, S. Rathee, T. Suman, M. Ahire, S. Madhav, M. S. Chauhan // Contemp Clin Dent. - 2018. - Vol. 9(4).—P. 597-600.

15. Twito, D. The effect of cigarette smoking habits on the outcome of dental implant treatment / D. Twito, P. Sade // PeerJ. — 2014.—Vol.2. — P. 546.

16. Naseri, R. Levels of smoking and dental implants failure: A systematic review and meta-analysis / R. Naseri, J. Yaghini, A. Feizi // J Clin Periodontol. — 2020.—Vol. 47 (4).- P. 518-528.

17. Shenava, S. Co-relation between smoking and bone healing around dental impants: A clinical study / S. Shenava, P. Singh, C. Sharath Babu, et al. // J Int Oral Health. - 2016. - Vol.8.- P. 1-3.

18. Cakarer, S. Investigation of the risk factors associated with the survival rate of dental implants/ Cakarer S., Selvi F., Can T., Kirli I., et al. // Implant Dent. — 2014. — Vol. 23(3).-P. 328-33.

19. Palacios-Garzón, N. Bone Loss in Implants Placed at Subcrestal and Crestal Level: A Systematic Review and Meta-Analysis / Palacios-Garzón N., Velasco-Ortega E., López-López J.// Materials (Basel).— 2019.—Vol. 12(1)._P. 154.

20. Chrcanovic, B. R. Smoking and dental implants: A systematic review and meta-analysis / B. R. Chrcanovic, T. Albrektsson, A. Wennerberg // Journal of Dentistry.2015. - Vol. 43(5).- P. 487-98.

21. Keenan, J. R. The impact of smoking on failure rates, postoperative infection and marginal bone loss of dental implants / J. R. Keenan, A. Veitz-Keenan // EvidenceBased Dentistry. - 2016. - Vol. 17(1). - P. 4-5.

22. Clementini, M. Systemic risk factors for peri-implant bone loss: a systematic review and meta-analysis / M. Clementini, P.H.O. Rossetti, D. Penarrocha, C. Micarelli, W. C. Bonachela, L. Canullo // Int. J. Oral Maxillofac. Surg. — 2014. — Vol. 43. - P. 323-334.

23. Mumcu, E. Effect of Smoking and Locations of Dental Implants on Peri-Implant Parameters: 3-Year Follow-Up / E. Mumcu, S. Ç. Dayan // Med Sci Monit. — 2019. — Vol. 25.-P. 6104-6109.

24. Liang, D. Effects of nicotine on the metabolism and gene expression profile of Sprague-Dawley rat primary osteoblasts / D. Liang, K. Wang, Z. Tang, R. Liu, F. Zeng, M. Q. Cheng, Wu H. Lian // Molecular Medicine Reports. — 2018. — Vol. 17(6). — P. 8269-8281.

25. Yang, J. Cigarette Smoke Extract Exposure: Effects on the Interactions between Titanium Surface and Osteoblasts / J. Yang, S. Y. Shao, W. Q. Chen, C. Chen, S. M. Zhang, J. Qiu // Biomed Res Int.—2019._- 2019:8759568.

26. Zhao, X. The Effect of Smoking Behavior on Alveolar Bone Marrow Mesenchymal Stem Cells of Clinical Implant Patient /X. Zhao, B. Zhu, Y. Duan, X. Wang, D. Li // Biomed Res Int. - 2018. - 2018:7672695.

27. Иванов, П. В. Современные представления об остеоинтеграции дентальных имплантатов / П. В. Иванов, Н. И. Макарова, Н. В. Булкина, Л. А. Зюлькина // Известия высших учебных заведений. Поволжский регион. Медицинские науки. — 2018. — № 4. — С. 205-217.

28. Самородская, И.В. «Парадокс» факторов риска развития сердечно-сосудистых заболеваний. Фокус на курение / И. В. Самородская, Е.Д. Баздырев, 0.Л. Барбараш // Комплексные проблемы сердечно-сосудистых заболеваний. — 2019. — T. 8, № 1.—C. 90-99.

29. Casado, P. L. Smoking as a Risk Factor for the Development of Periimplant Diseases/P.L. Casado, T. Aguiar, M. P. Fernandes Pinheiro, A. Machado, A. da Rosa Pinheiro // Implant Dent.—2019.—Vol.28(2).—P. 120-124.

30. Al-Zyoud, W. Salivary Microbiome and Cigarette Smoking: A First of Its Kind Investigation in Jordan /W. Al-Zyoud, R. Hajjo, A. Abu-Siniyeh, S. Hajjaj // Int J Environ Res Public Health. — 2019. - Vol.17(1)._- pii: E256.

31. Hanioka, T. Smoking and periodontal microorganisms / T. Hanioka, M. Morita, T. Yamamoto, K. Inagaki, P. L. Wang, et al. // Jpn Dent Sci Rev.— 2019.— Vol. 55(1). - P. 88-94.

32. Jiang, Y. The Impact of Smoking on Subgingival Microflora: From Periodontal Health to Disease /Y. Jiang, X. Zhou, L. Cheng, M. Li // Front Microbiol.— 2020.— Vol. 11. - P. 66 .

33. Горобец, С. М. Факторы риска развития воспалительных осложнений дентальной имплантации / С. М. Горобец, И. Г. Романенко, А. А. Джерелей, С. А. Бобкова, Д. Ю. Крючков, О. В. Горобец // Таврический медико-биологический вестник. - 2017. - № 2. - C. 208-214.

34. Pokrowiecki, R. Oral microbiome and peri-implant diseases: where are we now? / R. Pokrowiecki, A. Mielczarek, T. Zaręba, S. Tyski // Ther Clin Risk Manag.2017.-Vol.13.-P. 1529-1542.

35. Bain, C. A. Smoking and implant failure — Benefits of a smoking cessation protocol / C. A. Bain // Int J Oral Maxillofac Implants. — 1996. - Vol. 11.—P. 756-759.

36. Peleg, M. Healing in smokers versus nonsmokers: survival rates for sinus floor augmentation with simultaneous implant placement/M. Peleg, A. K. Garg, Z. Mazor // Int J Oral Maxillofac Implants. — 2006. - Vol. 21(4). - P. 551-9.

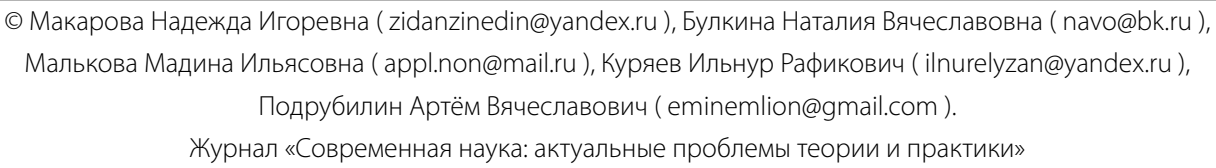

